\title{
MENSAJE LIBERADOR DE MONSEÑOR LEONIDAS PROAÑO*
}

\author{
Mons. Víctor Corral Mantilla1
}

\section{Introducción}

Han pasado 20 años de la muerte de Monseñor Leónidas Proaño, y su nombre, al igual que cuando vivía, sigue causando alegría y esperanza en unos y en otros inquietud y molestia. A la Iglesia de Riobamba nos sigue inspirando su vida, su testimonio, su praxis pastoral evangelizadora y liberadora; por eso seguimos celebrando su memoria, por eso estoy aquí para hablarles sobre "el mensaje liberador de Monseñor Leonidas Proaño".

\section{En qué contexto estamos celebrando esta memoria}

Celebramos esta memoria en contextos diferentes: Ecuador y el mundo no son los mismos que en tiempos de Monseñor Proaño.

- El desarrollo de la ciencia y la técnica ha sido inimaginable e impresionante.
- El mundo tenso y bipolar dominado por el marxismo y capitalismo ha dado lugar al dominio unipolar y globalizado del neoliberalismo.

- América Latina, después de sus luchas y frustraciones de las décadas del sesenta al noventa, vuelve a su búsqueda, hallar otros modelos sociales y políticos en Brasil, Venezuela, Bolivia, Ecuador, Argentina, Paraguay...

- Si bien es cierto que la calidad de vida de los pobres ha mejorado, sin embargo el porcentaje de excluidos del sistema aumentan.

- El cambio social más alentador y positivo se ha dado en el mundo indígena. El indígena chimboracense y ecuatoriano nada tiene que ver con el indígena que Monseñor Leonidas Proaño encontró al comienzo de su misión pastoral en 1954. La toma de conciencia de su inhumana situación y del derecho a su dignidad como hijos de Dios, fruto de la evangelización, su orga-

* Conferencia sustentada en el Teatro Universitario "Carlos Crespi" de la Universidad Politécnica Salesiana, con ocasión de conmemorar los 20 años de la muerte de Mons. Leonidas Proaño.

1 Obispo de la Diócesis de Riobamba. 
nización y sus pequeñas y grandes luchas reivindicativas, sin violencia (armada), pero con firmeza y unidad han logrado cambios trascendentales en la mentalidad y en el quehacer político y social no sólo de los indígenas, sino de todos los ecuatorianos.

- La Iglesia Latinoamericana de la opción por las mayorías pobres y creyentes en Medellín y la de los rostros sufrientes de Cristo, en Puebla, de la que fue partícipe y protagonista Monseñor Proaño, ahora es la Iglesia de los discípulos y misioneros de Cristo, en Aparecida, renovando y actualizando la opción con los nuevos rostros de pobres en el continente.

\section{Testimonio personal}

Tarea difícil y emotiva me resulta el dar testimonio de la vida de Monseñor Proaño. Es un ejercicio interno y vivencial, donde se entretejen los recuerdos. Me inspiró cuando joven estudiante, consolidando mi vocación al sacerdocio; su estilo pastoral iluminó mi trabajo pastoral ente los indígenas, cuando párroco; tuve el privilegio de ser su auxiliar en los 3 últimos años de su episcopado. Me honró con su amistad y confianza.

Su personalidad sencilla, su enorme capacidad de escucha, la austeri- dad de su vida entregada, su corazón libre y limpio de rencores, su firmeza y tenacidad para defender la verdad y la justicia encarnada en los pobres, víctimas del engaño y de la injusticia, su espiritualidad de seguidor de Jesucristo, nacida de la entraña del evangelio, impactaron mi fe y siguen alimentando e inspirando mi servicio episcopal.

Fue un hombre alegre, sincero, firme y constante en sus principios. Un cristiano seguidor de Jesucristo, apegado tenazmente al evangelio, un Obispo profeta "que de lo circunstancial de cada día supo pasar a los trascendental del futuro". Rompió esquemas y suscitó el cambio no sólo en las prácticas pastorales, sino en la mente y el corazón de los pobres e indígenas; el cambio que inició y propulsó no quedó sólo en los individuos, llegó hasta un cambio de mentalidad e incluso de estructuras en la Iglesia y en la sociedad.

Imposible comprender a Proaño y su obra sin la acción del Espíritu, sin la Iglesia, sin los pobres y sin los indígenas.

\section{Mensaje liberador de Monseñor Proaño}

¿Cuál sigue siendo el mensaje liberador de Monseñor Proaño a la Iglesia y a la sociedad ecuatoriana?, es el tema de esta conferencia. 
Para que haya mensaje es necesario que alguien lo transmita y para que sea liberador es necesario que el que recibe el mensaje se dé cuenta de sus esclavitudes, y se comprometa a ser libre.

Una premisa necesaria, para comprender todo lo que dijo Monseñor Proaño, es entender que su mensaje liberador no es otro que el del Evangelio de Jesucristo. Así, él lo entendió, vivió y proyectó en toda su existencia. No necesitó de ideología, de partido político, de medios poderosos.

Pero fueron los pobres y los indígenas, los que no sólo recibieron el Evangelio que él les llevaba, sino que, a su vez, ellos le evangelizaban: es decir, le hicieron conocer, amar y seguir mejor a Jesucristo.

La fidelidad a los pobres y a la Palabra de Dios hicieron crecer su espiritualidad, fueron origen de su profetismo e iluminaron toda su praxis pastoral.

De su vida, pensamiento y de su praxis pastoral, saco algunos aspectos que son mensaje liberador para la Iglesia de Riobamba, y que pueden serlo también para ustedes.

\section{Monseñor Proaño fue un segui- dor fiel de Jesucristo}

"Monseñor Proaño era un hombre de fe, tenía ideas muy claras extraídas del Evangelio, al que tomaba en serio de forma valiente cargando con las consecuencias. Tal era la raíz de la que surge su vida cotidiana y las acciones en los momentos decisivos.

Creyó en un Dios cercano, movilizador, horizonte último de la vida, de la justicia, del amor y la verdad. De ese Dios nos hablaba en sus homilías, en su oración frecuente y larga, en sus celebraciones con las comunidades.

Creyó en Él a la manera de Jesús: creer en el Padre era, sobre todo, hacer real y efectiva la voluntad de Dios en las cosas cotidianas y en las cosas profundas de la vida. Era creer en la dignidad de hijos que Dios otorga al hombre, también a los pobres y marginados por eso fue un apasionado defensor de la Vida, especialmente de la vida de los pobres de la provincia de Chimborazo y del País, porque pensaba que la miseria toca el corazón mismo de Dios, es la negación de su voluntad divina.

Por eso denunció el pecado, dijo que la miseria no es un destino natural de nosotros, sino el producto de estructuras injustas; es una ofensa a Dios porque es ofensa al hombre, al que da muerte y por eso es mortal.

Dada su fe en el Dios de la vida, en el Dios del Éxodo, el pecado estructural era la más profunda con- 
tradicción con su fe y por ello no abandonó el ministerio profético; por ello propició y luchó por soluciones justas a favor de los pobres, en especial los indígenas; creyó en un Dios sensible ante el clamor de los explotados, que baja a liberarlos. Esa voluntad divina de liberación tenía que ser hecha eficaz. Esta es la razón por la que estuvo del lado de los pobres, no por cálculo político sino basado en su fe en Dios liberador de los oprimidos.

Siendo un hombre de paz y a pesar de propiciar soluciones pacíficas, Monseñor Proaño aceptó por su fe, el misterio del conflicto que causa el pecado, y aceptó que ese pecado sólo puede ser superado mediante la lucha contra él

Por esa fe que busca la justicia asumió que los pobres, los de abajo, deben liberarse ellos mismos, como gestores de su propio destino. Arriba están los dioses del capitalismo absolutizado y sus servidores: en cambio al Dios de la liberación hay que encontrarlo abajo. Por esa su fe, Monseñor Proaño impulsó todos los movimientos justos del pueblo que lleven a su liberación, a la Nueva Sociedad de hombres nuevos, los hombres del Reino. Las federaciones de Cabildos, Cooperativas, federaciones, barrios, organizaciones juveniles, sintieron el apoyo del Obispo.
Creyó en el Dios de la Verdad, para ser libres y para tener la Verdad como arma de lucha exitosa, pues en su misma expresión conlleva la propia eficacia.

Monseñor Proaño creyó en el Dios de lo nuevo, no se asustó de la novedad de la historia, al contrario, hizo de esa novedad vehículo de su fe en Dios. Por eso, a nivel personal, supo crecer, cambiar y convertirse continuamente, para mostrar la verdadera humildad de los que creen en Dios. Vibraba siempre de manera nueva y distinta ante la experiencia de la fe y por eso comprendió de manera original su ministerio episcopal. En su gestión como Obispo, muchos reconocen lo novedoso de su acción y de su teología.

Monseñor Proaño creyó en el Dios de los pobres. Ellos son el camino para creer en Dios, y ellos fueron sus maestros en la fe, él mimo confiesa que fue evangelizado por los valores positivos que encontraba en ellos; en "los crucificados de la historia", en especial en los indígenas". (Cf. Mons. Proaño. Reflexiones sobre sus enseñanzas" P. Estuardo Gallegos)

\section{La opción por lo pobres}

Monseñor Proaño nació pobre, fue pobre y murió pobre, no por ma- 
la suerte, por destino o por desidia: su opción nace de la entraña misma del Evangelio, esto es de la Buena Nueva de Jesucristo.

Su opción fue radical, porque no admitía claudicaciones, pero nunca sectaria; por eso quienes quisieron dividir o crear violencia entre los pobres de América Latina, quisieron utilizarlo, pero no lo consiguieron.

Por esta opción pudo comprender a los pobres, iniciar la inculturación del evangelio entre los indígenas y sacar la cara por ellos en todo momento.

Nunca se dejó comprar o halagar por los poderosos.

Durante su vida jamás acumuló y guardó para si algún bien. Nunca tuvo nada propio, todo supo compartir con los pobres: su vida, su tiempo, sus capacidades... y todo cuanto tenía a su alcance y a su disposición.

Los pobres acudían a él, individual y colectivamente, para pedir una ayuda, para compartir sus tristezas y sobre todo para demandar un consejo o recibir una fuerza orientadora para seguir luchando.

Nunca le oí hablar mal de los pobres e indígenas; quejarse de ellos; todo lo contrario, proclamó en todos los foros del mundo sus valores, capacidades y el Proyecto de Dios sobre ellos para liberar y salvar el mundo y construir el Reino.
No se preocupó de construir obras materiales, pero dedicó todo su tiempo a evangelizar a los pobres (en el verdadero sentido de la palabra) a concientizar y a organizarlos para que ellos mismos, dejando de ser objetos del sistema, construyan su dignidad.

Luchó fuertemente para que su Iglesia particular y la Iglesia Latinoamericana y Universal sea pobre, se identifique con los pobres y sea seguidora de Jesucristo pobre.

El mismo en el libro, "Creo en el hombre y la Comunidad", que es una especie de autobiografía dice: "Ese amor y respeto a los pobres, particularmente a los indígenas, llegó a formar parte de mi propia existencia. Por esto he dicho que no he querido nunca ser traidor a los pobres...".

"Si antes dije que la pobreza es un don y que ese don tiene un sentido cuando viene acompañando del mensaje del evangelio, ahora digo que también la amistad de los pobres es un don y que también este don viene acompañando de un mensaje".

Con su ejemplo fiel y con su testimonio claro, la Iglesia de Riobamba mantiene la opción por los pobres e indigentes. Así lo reafirmamos en el Sínodo de Riobamba, que celebramos en 1996, con firmeza y convicción. 
Veinte años después de la muerte de Monseñor Proaño decimos: "Al igual que su Maestro, la Iglesia de Riobamba tiene como opción preferencial los pobres y el pueblo indígena. Desde ellos recibe la llamada permanente a la fidelidad, pues desde ellos el Señor evangeliza y son ellos los primeros llamados a la construcción del Reino. Debido a esto, es de necesidad absoluta, para la Iglesia de Riobamba, ver toda la realidad desde la óptica de los pobres y desde allí proyectar toda su práctica pastoral..." (Sínodo, Riobamba 72).

Puedo decirles con sinceridad que para nosotros, en la Iglesia de Riobamba los pobres y los indígenas constituyen, precisamente porque creemos y somos seguidores de Jesucristo, nuestra razón de ser, nuestro gozo y nuestra esperanza.

\section{Evangelización liberadora e inculturada}

Un tercer mensaje liberador que podemos sacar de Monseñor Proaño, es la evangelización liberadora e inculturada que él practicó. Se puede afirmar con toda justicia que Monseñor Proaño, fue un eximio misionero y evangelizador de este siglo.

Participante importante en el Concilio Vaticano II y en las Conferencias Latinoamericanas de Mede- llín y Puebla, comprendió y promulgó incansablemente que la Iglesia no estaba hecha para preocuparse por ella misma, sino para ser misionera, liberadora y salvadora del mundo en nombre de Jesús. Con Evangelii Nuntiandi, repetía constantemente a los Agentes de Pastoral que la tarea esencial, la razón de ser de la Iglesia es la evangelización.

Para él toda evangelización debe partir de la realidad concreta del pueblo y, después de analizarla con el mismo pueblo y confrontarla con el querer de Dios a través de su Palabra, tiene que llevar a la toma de conciencia de la situación de pecado y mal personal y social. Esta misma concientización impulsará en un segundo momento la organización, es decir la unión entre pobres para cambiar la realidad de egoísmo, muerte, injusticia, esclavitudes, tristezas en nuevas situaciones de amor, vida, justicia, libertad y gozo.

La finalidad última de toda evangelización, praxis pastoral y aún de toda acción cristiana debe ser el Reino de Dios, reconocido como don gratuito del Padre en Jesucristo, y por lo tanto como aceptación, conversión y seguimiento a la causa de Jesús.

La evangelización de Riobamba, que inició Mons. Proaño hace más de treinta años es liberadora por dos razones: 
- Porque parte de las realidades de injusticia y opresión de los pobres y con la palabra de Dios les abre los ojos, les une y organiza y les enseña a caminar en búsqueda de liberación.

- Y porque debe producir cambios no solo a nivel personal, sino también, a nivel social y estructural. Una evangelización así entendida y practicada hace nacer cristianos con coherencia entre fe y vida.

"Entiendo, dice Monseñor Leonidas Proaño, la fe cristiana para un sacerdote, para un Obispo, como para cualquier seglar, no simplemente como una aceptación intelectual de verdades reveladas; entendemos aquí la fe cristiana como una respuesta del hombre a Jesucristo nuestro liberador. Entiendo la fe cristiana como una respuesta de compromiso con el Evangelio".

De este tipo de evangelización liberadora necesariamente nace una Iglesia renovada, comunitaria y misionera del mundo y se supera un modelo de Iglesia que se asfixia por querer sólo conservarse y mantenerse, dispuesta únicamente a modernizar sus métodos de acción pastoral pero, a la larga, siempre centrada en sí misma.
Vemos con gozo que nace una nueva imagen de Iglesia más sencilla, más libre, menos privilegiada y más pobre, porque los pobres la asumen como suya y, a su vez, ella misma comprende que su fuerza, animo y esperanza está en los pobres, ya que entre ellos es donde mejor se descubre a Jesucristo como liberador y salvador. Sobre todo nace y se manifiesta una Iglesia de base y comunitaria.

"Abiertas estas comunidades cristianas a los problemas de su ambiente, experimentan que Cristo, es verdaderamente liberador, porque ellos mismos se van liberando de todas las opresiones de pecado y van contribuyendo a la liberación de los hombres que viven en su ambiente. Se vuelve así palpable la acción actualizada de la liberación de Cristo. Y entonces las comunidades cristianas celebran el acontecimiento salvífica con una liturgia que queda lejos del simple ritualismo. Desde allí, desde el gozo de sentirse salvados, salen las comunidades cristianas enardecidas para anunciar de palabra y con el testimonio de su vida que el reino de Dios está cerca". (Proaño: conferencia: Perspectiva para la Iglesia Latinoamericana desde la Teología de la Liberación). 


\section{Evangelización e inculturación en Monseñor Proaño}

Donde la evangelización liberadora, como semilla fecunda regada por Monseñor Proaño, cayó en tierra fértil, fue en el pueblo indígena de la provincia del Chimborazo, lugar en el que está ubicada la Diócesis de Riobamba.

Al comienzo decía que el mensaje para que sea liberador tiene que ser aceptado y apropiado por personas y pueblos que tengan esclavitudes y opresiones y quieran liberarse.

Y esto sucedió en el pueblo indígena de Chimborazo y Ecuador con la bendita presencia y acción pastoral de Monseñor Leonidas Proaño.

Con la habilidad de escritor que tenía, al poco tiempo de haberse hecho cargo de la Diócesis (10-101954) describe de esta manera la situación de los indígenas que eran el $70 \%$ de sus diocesanos.

"El problema del indio es complejo y formidable, y no hay como, ni quiero darle soluciones parciales. $\mathrm{Su}$ situación es para llorar... viven, ¡Señor, como viven!, en chozas del tamaño de una carpa o como topos dentro de huecos cavados en la tierra. Explotados sin misericordia por los grandes millonarios de la provincia, quienes después de vender sus cosechas se largan a Quito, Guaya- quil y a las grandes ciudades de América y Europa, a malgastar el dinero exprimido de ese miserable estropajo que es el indio del Chimborazo... Cuando lo veo siento oprimido el corazón y adivino lo formidable que es el problema de su redención".

Esta realidad injusta y tremendamente contrastante con el resto de la población ecuatoriana, hizo que Monseñor Proaño, con su Iglesia, hiciera un cambio radical de la pastoral tradicional a un nuevo estilo de pastoral que opta decididamente por los más pobres entre los pobres: los indígenas...

Monseñor Proaño fue soñador y dinamizador de una Iglesia indígena libre y liberadora. No sólo habló de formación de comunidades y de evangelización liberadora, sino que en su praxis pastoral organizó numerosas Comunidades Eclesiales de Base y mediante una pastoral de conjunto, formó múltiples misioneros laicos, catequistas, dirigentes de organizaciones populares, educadores populares, etc...

Desde entonces la pastoral de la Iglesia de Riobamba, ha ido pasando, de una pastoral para los indígenas a una pastoral con y desde los indígenas.

Inculturar el evangelio de Jesucristo en los pueblos indios a partir de las experiencias de Dios y las se- 
millas del Verbo, para construir la iglesia con agentes, teología, liturgia y estructura propias, han sido el objetivo, esfuerzo y realización que, lenta pero constantemente, hemos ido haciendo como Iglesia de Riobamba.

Y, junto a todo esto, también como misión liberadora de la Iglesia, hemos y estamos impulsando la organización indígena, fomentando el sentido de identidad y conciencia del pueblo quichua, con cultura, economía y política propia, en vista de la transformación de la sociedad, potenciando sus justas iniciativas y acciones, especialmente el derecho a la tierra y a la comercialización directa.

$\mathrm{La}$ realidad indígena que Monseñor Proaño encontró en 1954, en la actualidad es diferente gracias a la siembra que el comenzó y que la Iglesia de Riobamba continúa.

Poco tiempo antes de morir, al recibir un Doctorado Honoris Causa en Alemania, con sencillez y alegría describía de esta manera la realidad de los indígenas a los que tanto amó y había ido entregando sacrificada e incomprendidamente su vida de apóstol y profeta; decía: “ ... He sido testigo, durante más de treinta años, del poder liberador del Evangelio, vale decir de la continuidad de realización de los signos con que Cristo acompañaba la proclamación de la Buena Nueva a los pobres. Práctica- mente, quienes estuvieron ciegos, ahora ven; quienes habían perdido la palabra, por causa de la opresión y estaban mudos, ahora hablan; quienes se sentían tullidos y paralíticos porque habían sido maltratados durante siglos, ahora caminan y se organizan como pueblo".

A este nuevo tipo de indígena es al que la Iglesia de Riobamba está acompañando, siguiendo las huellas de este gran Obispo, profeta y apóstol de nuestros tiempos, calificado con razón Obispo de los Indios.

\section{Profetismo de Monseñor Proaño}

Para terminar deseo señalar un último mensaje liberador de Monseñor Proaño: su profetismo.

Supo responder a su vocación, que fue descubriendo y a la que fue respondiendo progresivamente. Es uno de los grandes profetas que Dios suscitó en nuestra América Latina en la segunda mitad de siglo XX. Quería que la Iglesia y el pueblo entero fuera profético, es decir participante de la misión profética de Cristo.

Desde su propia experiencia escribe lo siguiente: "Profeta es el hombre que ve. Es el hombre que ve en primer lugar a Dios, con quién conversa en la oración como con un amigo, con su amigo; el hombre que, por lo mismo, descubre cuáles son 
los designios de Dios, cuál es su voluntad, cuáles son sus planes". "Profeta es el hombre que ve las realidades de este mundo en toda su objetividad, el que no se deja deslumbrar por falsos valores ni desorientar por falsas promesas. Es el que ve la mentira en donde quiera que exista. Es el que ve la trayectoria que sigue la historia y prevé las consecuencias de los hechos actuales, porque sabe mirar el hoy en función del mañana y en función de lo eterno".

"El profeta no encuentra eco ni comprensión en los hombres que le rodean..."; "los profetas continúan siendo perseguidos y no sólo incomprendidos".

Quienes conocimos a Monseñor Proaño, sabemos que todo lo que dice nació de la entraña misma de su dolorosa experiencia.

Fiel en su seguimiento a Jesucristo y pegado como era al Evangelio, no tuvo miedo de ejercer su función de profeta que denuncia el mal de la sociedad y aún de su propia Iglesia, señalando sus causas y responsables.

A consecuencia de esto tuvo que sufrir incomprensiones, calumnias, persecuciones y abandono de ajenos y propios.

Se le acusó de Obispo Rojo, subversivo, agitador de los indios, comunista...
$\mathrm{Al}$ respecto es preciosa la defensa que hace de su acción pastoral respondiendo a las acusaciones... "Se me acusa de ser un Obispo Comunista. Comunista porque he trabajado por el indio; comunista porque he trabajado por el pobre, comunista porque se ha realizado la Reforma Agraria que se está llevando a efecto en la Diócesis, comunista porque estoy abriendo los ojos a quienes estaban viviendo en las tinieblas, comunista porque estoy realizando una obra de concientización, una obra de educación de los hombres, una obra de educación liberadora, como no tengo vergüenza de decirlo sino más bien orgullo. Liberación de los hombres por todo el sistema de concientización, de personalización; de que los hombres aplastados empiecen a pensar por sí mismos, de que los hombres que no tenían palabra empiecen a recuperar y a hablar de que los hombres que casi no sentían necesidades empiecen a sentirlas, y no solamente sus necesidades sino también a ser conscientes de sus derechos y a reclamarlos delante de quien quiera". (Discurso: ¿Cuál es la razón de tanta calumnia? 10 de junio 1972).

Cuanta falta hacen hoy hombres de la talla de Monseñor Proaño.

Nuestros pueblos necesitan hoy profetas para alzarse del someti- 
miento y la esclavitud de los sistemas de muerte a la indignación propia de su condición cristiana. Necesitan profetas para conquistar su libertad con la memoria de Jesús, el crucificado que resucitó.

También nuestra Iglesia, para ser sacramento salvador del mundo actual, necesita la profecía para ser fiel a los pobres, al pueblo sufrido, a su Cristo y a su Dios.

Necesitamos recuperar la dimensión histórica y teológica de la profecía para desenmascarar el pecado de la sociedad y sus responsables y para ofrecer una esperanza para el futuro, basada en el Dios de la vida que libera y salva por su Cristo y por los que le siguen en el camino de la cruz.

\section{Conclusión}

Es necesario, diría indispensable, hacer memoria de la vida, pensamiento y acción pastoral de Monseñor Proaño.

La Iglesia de la que fue Obispo y a la que amó fielmente, a pesar de las incomprensiones y sospechas a la línea liberadora de su pastoral, de algunos de sus miembros, necesita ha- cer presente su memoria y mantener su legado para hacer sentir su proximidad y cercanía al pueblo pobre tanto del campo como de las periferias urbanas, "no sólo con el socorro a sus necesidades más urgentes, sino con la defensa clara y valiente de sus derechos" (cf.550. D.A.).

Los Pueblos Indios, que con la fuerza de sus reivindicaciones se han ganado su merecido puesto en la sociedad ecuatoriana, pero que tienen aún un largo camino que hacer para consolidar su unidad interna, defender su identidad y seguir luchando contra la pobreza y marginación, necesitan hacer memoria y mantener el legado de Mons. Proaño.

Los ecuatorianos, sobre todo de los sectores populares, cansados de un modelo político y económico que ya no da más, buscan cambios profundos que den lugar a un Ecuador diferente, más humano, solidario, participativo, incluyente. Este nuevo Ecuador necesita hacer memoria y mantener el legado de Monseñor Proaño. Sigue resonando su vibrante pedido: "BUSCO SONADORES, QUE AYUDEN A CONSTRUIR LA SOCIEDAD NUEVA". 